\title{
EDUCAÇÃO DE JOVENS E ADULTOS E NOVAS TECNOLOGIAS DA INFORMAÇÃO: UMA ABORDAGEM EDUCACIONAL
}

\author{
C. B. SILVA* , C. H. M. SOUZA E G. T. CARMO \\ Universidade Estadual do Norte Fluminense Darcy Ribeiro (UENF) \\ cristianabarcelos@yahoo.com.br*
}

Artigo submetido em janeiro/2015 e aceito em fevereiro/2016

DOI: $10.15628 /$ holos.2016.2666

\section{RESUMO}

A instituição escolar tem sido apontada como o lócus de estudos e análises de fenômenos educacionais. As implicações aqui discutidas fizeram parte de uma pesquisa cujo objetivo foi compreender como os professores da Educação de Jovens e Adultos (EJA) se posicionavam frente ao desafio da utilização das novas tecnologias da informação e da comunicação na prática educacional, após a proposta de programa denominada "Nova EJA", implementada pela Secretaria de Estado de Educação do Estado do Rio de Janeiro (SEEDUC). Os sete questionários foram analisados com base nos estudos do novo papel do professor de Lévy (1993, 2005) e das competências e habilidades necessárias à prática docente de Tardif (1991, 2000, 2014). Os resultados assinalaram que para além da infraestrutura necessária ao uso das tecnologias na escola, os docentes apontaram para a necessidade de construção de conhecimentos nos cursos de formação profissional inicial, sendo entendido como uma das formas de viabilizar uma atuação pedagógica que relacione positivamente educação e novas tecnologias.

PALAVRAS-CHAVE: Educação de Jovens e Adultos. Tecnologias de informação. Prática Docente.

\section{YOUTH AND ADULT EDUCATION AND NEW INFORMATION TECHNOLOGIES: AN APPROACH EDUCATIONAL}

\begin{abstract}
The school has been identified as the locus of studies and analysis of educational phenomena. The implications discussed here were part of a study that aimed to understand how teachers of Youth and Adult Education positioned themselves to the challenge of the use of new information technologies and communication in educational practice, named after the program proposal "New EJA", implemented by the State of Rio de Janeiro State Education. The seven questionnaires were analyzed
\end{abstract}

based on studies of the new role of the teacher Lévy $(1993,2005)$ and the competencies and skills necessary for professional practice of Tardif (1991, 2000, 2014). The results indicated that in addition to the infrastructure necessary for the use of technology in school, the teachers pointed to the need to build knowledge in initial vocational training courses, being understood as a way of enabling an educational activity that positively relate education and new technologies.

KEYWORDS: Education for Youth and Adults. Information Technology. Educational Practice. 


\section{INTRODUÇÃO}

Este trabalho procurou analisar e discutir quais características os professores do Programa "Nova EJA", elencavam como necessárias para a utilização das novas tecnologias da informação e da comunicação com fins educacionais no ambiente escolar.

Sobre o emprego dos recursos tecnológicos para fins educativos, documentos como os Parâmetros Curriculares Nacionais (PCN's) publicados em 1996, recomendavam no Brasil o uso das tecnologias, quando assinalavam que elas deviam estar inseridas nos currículos e nas disciplinas, uma vez consideradas instrumentos de aprendizagem na educação escolar (BRASIL, 1999).

Documentos legais na década de 90 apresentavam e sugeriam diretrizes norteadoras que de certa forma, influenciariam a prática docente. Assim sendo, foi na relação prática com o discente que a necessidade do uso de diversos recursos tecnológicos pareceu emergir, trazendo para o universo da sala de aula uma infinidade de equipamentos multimídia, como reforçou Castell (2005, p. 338): "Os estudantes trazem os seus portáteis equipados com sistemas wireless para as salas de aula."

Pensando nessas questões, inicialmente tratamos da inserção de recursos tecnológicos na educação com objetivos pedagógicos. Em seguida, analisamos alguns estudos históricos dos autores e pesquisadores que relacionavam Educação de Jovens e Adultos (EJA) e novas tecnologias da comunicação e da informação. Posteriormente, consideramos as especificidades de um programa de EJA, denominado "Nova EJA" implementado a partir do ano de 2013, pela Secretaria de Estado de Educação do Rio de Janeiro (SEEDUC). Por último, apresentamos a apreciação de um grupo de professores da rede pública estadual, em relação ao uso das tecnologias, após a implementação do programa.

\section{TECNOLOGIAS DA INFORMAÇÃO E DA COMUNICAÇÃO NA EDUCAÇÃO}

O uso das tecnologias de informação e comunicação nas escolas, não é tão recente e não teve início com a democratização do acesso aos computadores. Do ponto de vista conceitual, recorrendo a Carneiro (2002), percebemos que usou o termo tecnologias para se referir aos recursos como lousa, giz, livro didático, lápis, exposição oral e, ainda, a própria instituição escolar. Para a autora, tais recursos faziam parte da tecnologia da educação, juntamente com a TV, o retroprojetor, o vídeo e o computador.

Nesse sentido, a pesquisadora Tajra (1998) ao discutir sobre a questão, argumenta que a informática na educação passou a ser objeto de estudos no Brasil no final da década de 1970, a partir do projeto Educação com Computador (EDUCOM). Considerada primeira iniciativa oficial de estimular a inserção de computadores nas escolas públicas.

Ainda tratando sobre ao uso da tecnologia no país, Carneiro (2002, p. 49) garantiu que "(...) no início da década de 80, começa a desenvolver-se a Política de Informática Educativa (PIE), caracterizada por atividades de pesquisa e seminários de discussão em pequena escala." Apontou 
também, para o Programa Nacional de Informática na Educação (PROINFO) e para os PCN's como manifestações legais, da preocupação do governo brasileiro com o uso das tecnologias na educação. Também destacou que das razões para a implantação do uso das tecnologias nas escolas, estavam à necessidade de aproximação entre a escola e novos paradigmas sociais no que se refere ao armazenamento, à transformação, à produção e à transmissão de informações.

Quanto à postura dos professores frente à implantação do uso dessas tecnologias e as suas contribuições para o processo pedagógico, Niskier $(1993$, p. 45) assinalou que o principal motivo de resistência poderia ser a possibilidade de serem substituídos pelos recursos tecnológicos, quanto a esse assunto, o autor se posicionou da seguinte maneira: "O uso do computador na educação está em plena ascensão em diversos países. O receio inicial de que a máquina poderia vir a substituir o professor aos poucos está sendo desmistificado".

Em relação as tecnologias, de modo geral, Blikstein e Zuffo (2003) afirmaram que elas podiam seduzir e encantar, à medida que pareciam cativar os profissionais da informática, do comércio eletrônico, os web-jornalistas e alguns educadores.

No que se refere à aplicação das tecnologias no Brasil, Kenski (2003, p. 70) explicou que em sua maioria, eram aplicadas de maneira impositiva e como estratégia não-pedagógica. Na visão da pesquisadora, elas na verdade eram "(...) impostas, como estratégia comercial e política, sem a adequada reestruturação administrativa, sem reflexão e sem a devida preparação do quadro de profissionais (...)". Destacou que para um uso efetivo e eficaz das tecnologias na educação, era necessário mais que infraestrutura tecnológica.

Para além dessas questões, Ponte (2000) ampliou alguns dos pontos relacionados a esse assunto, quando problematizou a integração das tecnologias na escola e defendeu que, para além dos questionamentos sobre a relação entre as tecnologias e os objetivos da instituição escolar, estariam às formas de aprendizagem, e questionamentos como: De que modo às tecnologias da informação alteram a natureza dos objetivos educacionais visados pela escola? Como modificam as relações entre os alunos e o saber? Elas modificam as relações entre alunos e professores? Podem variar o modo como os professores vivenciam sua profissão?

Sobre a profissão professor, na visão de Masetto (2004, p. 134), por muito tempo acreditouse que educar significava transmissão de conhecimento organizado e sistematizado. Exigia-se do aluno tarefas ligadas à memorização e reprodução de informações. Decorrente dessa visão, nos cursos de formação inicial para professores, percebia-se "(...) por parte dos alunos a valorização do domínio de conteúdo nas áreas específicas em detrimento das disciplinas pedagógicas". Para o estudioso, o desprestígio das disciplinas pedagógicas talvez fosse reforçado, pela postura dos professores formadores dos cursos de licenciatura. De acordo com ele,

Nos próprios cursos de ensino superior, o uso de tecnologia adequada ao processo de aprendizagem e variada para motivar o aluno não é tão comum, o que faz com que os novos professores do ensino fundamental e médio, ao ministrarem suas aulas, praticamente copiem o modo de fazê-lo e o próprio comportamento de alguns de seus professores de faculdade, dando aula expositiva e, às vezes, sugerindo algum trabalho em grupo com pouca ou nenhuma orientação (p.135). 
Necessário ressaltar a contribuição de Lévy $(2005$, p.170) para a questão, que ao falar sobre o novo papel do professor, trouxe a noção da aprendizagem cooperativa, explicando que os “(...) professores aprendem ao mesmo tempo em que os estudantes e atualizam continuamente tanto seus saberes 'disciplinares' como suas competências pedagógicas". O autor apresenta com seus estudos, a necessidade de se discutir à função do professor e seu posicionamento frete aos desafios propostos para a educação.

Assim, com essa demanda de mudança da função do professor, de especialista que possuía e transmitia o conhecimento para o de mediador, incentivador e orientador no processo de ensinoaprendizagem, emergem novas e diferentes exigências (MASETTO, 2004).

Ainda se tratando do profissional professor, Ramal (2002) explicou a nova postura do professor com a expressão "arquitetos cognitivos":

O arquiteto cognitivo: (a) é um profissional; (b) capaz de traçar estratégias e mapas de navegação que permitam ao aluno empreender, de forma autônoma e integrada, os próprios caminhos da construção do (hiper) conhecimento em rede; (c) assumindo, para isso, uma postura consciente de reflexão-na-ação; e (d) fazendo uso crítico das tecnologias como novos ambientes de aprendizagem (RAMAL,2002, p. 191, apud LÉVY 1993).

Na mesma perspectiva, para Tardif (1991, p. 221) os conhecimentos, competências e habilidades constitutivas da prática dos professores denominam-se "saberes docente". Para ele “(...) o(a) professor(a) padrão é alguém que deve conhecer sua matéria, sua disciplina e seu programa, que deve possuir certos conhecimentos das ciências da educação e da pedagogia, sem deixar de desenvolver um saber prático fundado em sua experiência cotidiana com os alunos." Sendo assim, parece coerente considerar que compreendido como objeto de estudo, a tecnologia da informação e da comunicação na educação, precisa ser discutida, analisada e aprofundada, tanto nas instituições escolares, quanto na universidades.

\section{HISTÓRICO DA RELAÇÃO ENTRE EDUCAÇÃO DE JOVENS E ADULTOS E NOVAS TECNOLOGIAS}

Relacionar as novas tecnologias da informação e da comunicação na educação parece ser uma tarefa com inúmeras implicações. No caso de estabelecer sua ligação com a EJA, significa romper com a concepção de uma educação voltada para jovens e adultos fracassados, e apontar para a formação de um cidadão crítico e participante do seu tempo. Embora sejam incipientes as pesquisas sobre esta temática, alguns autores do campo apontam para a necessidade deste tipo de investigação. Bélanger (1996) sugeriu que as perspectivas mundiais de investigação no campo EJA, indicam a necessidade de avaliação do potencial para o uso de novas tecnologias da comunicação e da informação nessa modalidade, como tema de investigação de alcance internacional.

O trabalho de Cavanagh (1997) apresentado no V Conferência Internacional de Educação de Adultos (CONFINTEA), demonstrou que um dos pontos importantes desta temática, refere-se a como fazer das numerosas mudanças observadas na EJA, oportunidades para melhorar a 
participação e a prática. Discutiu a necessidade das novas tecnologias atenderem cada cultura especificamente, não ficando subordinada a cultura do norte e do ocidente, atendendo assim a diversidade. Afirmou ser fundamental apoiar a elaboração de programas educativos.

A pesquisadora Gomez (1999) do Instituto Paulo Freire, explicou que linguagem, comunicação e elementos comunicacionais formam um dos eixos fundamentais da proposta educativa para ajudar os sujeitos a libertarem-se da manipulação e domesticação, desenvolvendo sua capacidade crítico-reflexiva. Reconheceu a proposta de Paulo Freire como uma alternativa em relação à incorporação da informática na própria ação educativa.

O professor Gadotti (1998), afirmou que Freire buscava fundamentar o processo de ensinoaprendizagem através de ambientes interativos e do uso de recursos audiovisuais. Reforçou o uso de novas tecnologias, principalmente o vídeo, a televisão e a informática.

Segundo Knobel (1998) pensar a educação, as novas tecnologias e o fenômeno da comunicação, significa interessar-se pela prática libertadora enquanto dimensões de mediação e engajamento educacional.

Ainda sobre a discussão em torno de uma educação libertadora, iniciou-se um debate referente a uma teoria intitulada "Pedagogia da Comunicação", inaugurada em 1972 pelo espanhol Francisco de Gutierrez. Interessante ressaltar que ela nasce sobre influência da "Pedagogia Libertadora" de Freire, e das investigações sobre outros tipos de comunicação diferentes daquelas fundamentadas na oralidade e na escrita (BRASILEIRO, 2002).

Após a década de 70, momentos de esperança na tecnociência -“ (...) um recurso de linguagem para denotar a íntima relação entre ciência e tecnologia" (OGIBOSKI, 2012, p.23) - eram tão reais que ecoavam nas conferências internacionais sobre EJA. Uma delas foi a Conferência de Elsinore (1949) realizada na Dinamarca (período anterior à televisão), que debateu a importância dos meios audiovisuais e de comunicação de massa dirigidos ao desenvolvimento da compreensão internacional e dos valores de solidariedade, assim como as melhorias materiais e necessidades comuns. Em Montreal (1960), discutiu-se a utilização do cinema, do rádio e da televisão como meios pedagógicos. Em Tóquio (1972), voltamos a encontrar a afirmação da grande importância dos meios audiovisuais na EJA. Ainda na Conferência de Paris (1985), continua aparecendo o rádio, a televisão e em geral, os meios de comunicação de massas, como grandes esperanças para atender às demandas de alfabetização e o desenvolvimento de programas de EJA a baixo custo (IRELAND, 2013).

Destarte, a importância da utilização de novas tecnologias na EJA, não implicou numa aceitação acrítica destes meios. Embora discutido em todas as conferências acima citadas, não percebemos a efetividade dos recursos da tecnologia educativa na educação de pessoas jovens e adultas, que sob a perspectiva de Freire (1997, p. 20), deviria na prática educativa, desafiar os alunos a construírem uma compreensão crítica de sua presença no mundo. Para ele, a escola necessitaria ser um local de se pensar criticamente o saber tecnológico, tanto que para o militante de uma educação crítica: "É tão urgente quanto necessária à compreensão correta da tecnologia, a que recusa entendê-la como obra diabólica ameaçando sempre os seres humanos ou a que perfila como constante a serviço de seu bem estar". 


\section{A POLÍTICA DE EJA NO ESTADO DO RIO DE JANEIRO}

A trajetória da educação no Brasil relacionada à EJA acabou muitas das vezes, por atenuar na prática, ainda mais, os processos de exclusão e marginalização social que sofriam os jovens e adultos que se encontravam excluídos das instituições sociais escolares (ARROYO, 2007).

No s primeiros anos do século XXI, em termos legais, a EJA emerge como modalidade de educação na Constituição Federal de 1988, na Emenda Constitucional n 59/2009 e, sobretudo na Lei de Diretrizes e Bases da Educação Nacional (LDBEN 9.394/96). A partir desses instrumentos legais, ficou determinado que os sistemas de ensino assegurassem gratuitamente aos jovens e aos adultos, que não puderam efetuar os estudos na idade regular (BRASIL, 1996).

Em termos específicos, fundamentado na legislação brasileira que trata da EJA, e em alguns dados apresentados no Plano Estadual de Educação do Rio de Janeiro, foi que o governo do estado, através da SEEDUC, implementou em 2013, um Programa chamado "Nova EJA". Foi organizado com a perspectiva de consolidar uma escola de qualidade, contextualizada e capaz de preparar os jovens e adultos para o mundo do trabalho.

A proposta foi fruto da Resolução SEEDUC de no 4951 de 04 de Outubro de 2013. Na ocasião, o Secretário de Estado de Educação, Vossa Excelência, o Sr. Wilson Risolia Rodrigues no uso de suas atribuições legais e tendo em vista o processo $n=E$ 03/001/5612/13, fixou diretrizes para implantação de novas matrizes curriculares para a EJA enquanto modalidade da Educação Básica nas unidades escolares da rede pública.

Analisando a proposta de EJA, percebemos que do ponto de vista teórico-metodológico, ela trouxe novidades, tanto para os discentes, quanto para os docentes. Apresentou uma nova matriz “(...) alinhada com essa modalidade educacional, bem como estratégias de aprendizagens compatíveis com as mídias e exigências do século XXI (MANUAL DO PROJETO NOVA EJA, 2013, p.5). Além de contar com fundamentos teóricos diferenciados, a intenção, era oferecer materiais didáticos próprios para alunos e professores (uma novidade para a EJA da rede), modificar a estrutura e tempo das aulas para o Ensino Médio (estrutura dos cursos divididos em módulos e hora-aula igualada ao do Ensino Médio regular diurno), oferecer curso de formação continuada para os professores e estimular o uso contínuo de tecnologias da informação e da comunicação no processo de ensino-aprendizagem.

Com a intenção de compreender os impactos da proposta no trabalho dos professores matriculados no curso de formação e que atuavam na "Nova EJA", apresentaremos a seguir, algumas das impressões de um grupo de docentes -lotados em uma escola estadual de Educação Básica, localizada na cidade de Campos dos Goytacazes-RJ-, sobre o uso das tecnologias na prática educacional, após a implementação pela, do programa "Nova EJA".

\section{O OLHAR DOS DOCENTE DA "NOVA EJA" E AS TECNOLOGIAS DA INFORMAÇÃO E DA COMUNICAÇÃO}

$\mathrm{Na}$ intenção de discutir questões relacionados a apreciação de um grupo de professores da rede pública estadual, em relação ao uso das tecnologias, após a implementação do programa 
"Nova EJA", aplicamos um questionário constituído por dez perguntas fechadas e abertas, divididas em duas partes:

1ㅁ - Identificação: sete perguntas relacionadas a sexo, área de atuação, titulação, ano de formação, situação funcional e ano de ingresso na instituição, tempo de trabalho no programa "Nova EJA" e se participaram do curso de formação continuada oferecido pela SEEDUC.

2a - Linguagens e tecnologias da informação na educação: cinco perguntas fechadas e cinco abertas e um espaço para comentários livres sobre o assunto da pesquisa. As perguntas fechadas abordavam as seguintes temáticas: recursos tecnológicos dispostos na escola e utilizados em sala de aula; utilização de ambientes virtuais pelos docentes fora da escola e dentro para atividades educacionais; fatores que impediam ou dificultavam o uso das tecnologias na prática profissional dos profissionais. Nas perguntas abertas indagou-se a respeito das características indispensáveis para a utilização das tecnologias com fins educacionais; aspectos positivos e negativos do uso das tecnologias na educação; utilização de recursos educativos multimídia utilizados pelos docentes e sites consultados ou indicados para os discentes.

\subsection{Perfil dos participantes da pesquisa}

A escola pertencia à rede pública estadual, possuía cerca de 3000 alunos e 120 professores no total. No programa "Nova EJA", na ocasião da coleta de dados, haviam 4 turmas, sendo 80 alunos matriculados e 12 professores. Dos docentes, 7 participaram da pesquisa, conforme gráfico abaixo:

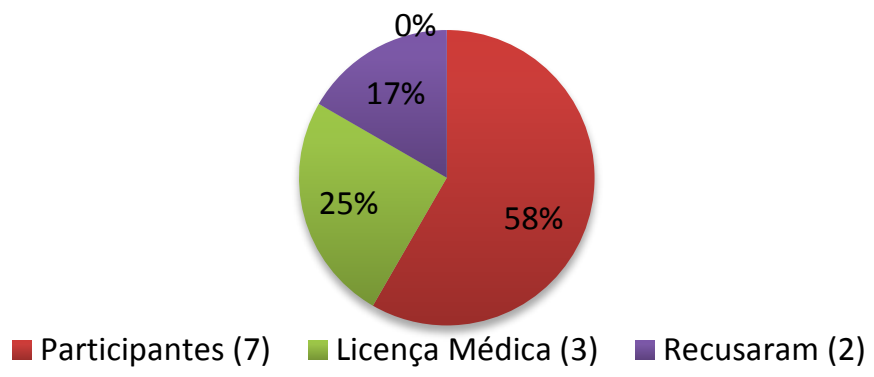

Gráfico 1: Universo da pesquisa

Fonte: elaborado pelos autores.

Com base nos dados fornecidas na primeira parte do questionário, foi possível traçar um perfil do grupo participante. Era composto por: 2 professores (homens) e 5 professoras (mulheres) que atuavam no Ensino Médio. Tinham a seguinte titulação formação: 2 graduação; 3 especialização e 2 doutorado, conforme gráfico 2:

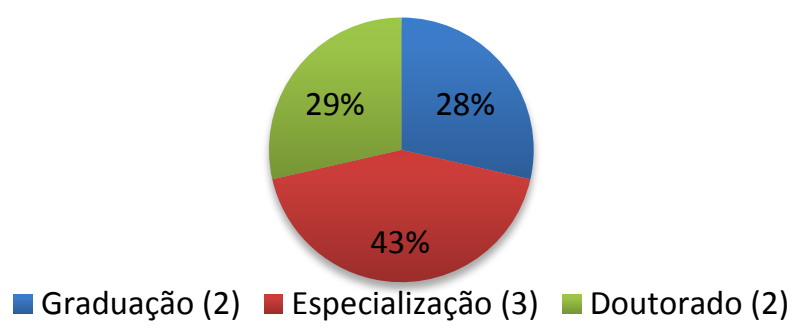

Gráfico 2: Formação dos Participantes

Fonte: elaborado pelos autores. 
Em relação à data de ingresso na instituição variavam entre 2007 a 2014, e os anos de conclusão da formação, alternavam entre 2000 a 2011. Atuavam na escola, profissionais com pouco mais de quatorze anos de experiência e recém-formados.

As disciplinas ministradas pelos docentes eram relacionadas a estruturação definida nos Parâmetros Curriculares Nacionais para o Ensino Médio (BRASIL, 1999), sendo elas: i) área de linguagens, códigos e suas tecnologias: Educação Física e Língua Portuguesa, - totalizando 2 professores nessa área; ii) área de ciências humanas e suas tecnologias: Filosofia, Geografia, Sociologia - totalizando 3 professores nesse grupo e ; iii) área de ciências da natureza, matemática e suas tecnologias: Biologia e Química - totalizando 2 professores nessa área. Os dados demonstraram que o grupo que se dispôs a participar da pesquisa era bastante heterogêneo quanto à formação e atuação.

\subsection{Recursos tecnológicos utilizados pelos docentes}

A partir das respostas coletadas, percebeu-se que os recursos tecnológicos mais utilizados, nas atividades com os alunos eram o data show. Do total de respostas, $57 \%$ disse ser o data show o recurso empregado com mais frequência. A televisão apareceu em segundo lugar, contabilizando $43 \%$. Em terceiro, ficou o DVD e computador, ambos com $28 \%$ das opções. O aparelho para CD e os recursos como gravador, filmadora e rádio foram citados por $28 \%$ ou menos dos professores.

Válido ressaltar que dentre os docente, $71 \%$ informaram ter conhecimento de que a escola dispunha de computadores em rede e com internet, entretanto, menos da metade disse fazer uso de tal recurso em suas aulas - o mesmo percentual de profissionais que afirmou utilizar ambientes virtuais para desenvolver atividades com os alunos. Esse dado contrastou com os $86 \%$ que disseram utilizar ambientes virtuais para atividades como comunicação pessoal, atualização, formação e lazer. $\mathrm{O}$ uso do e-mail foi apontado por $71 \%$ dos docentes como ambiente virtual mais utilizado na escola, sendo que $90,62 \%$ deles, afirmaram usar o email para atividades pessoais, e apenas $57 \%$ dos docentes informaram utilizar esses ambientes virtuais para desenvolverem atividades com os alunos.

Dentre os professores que disseram não utilizar nenhum ambiente virtual para atividades com alunos (43\% do total), o motivo recorrente nas justificativas foi à falta de infraestrutura na escola e o tempo, como se pode constatar nos seguintes depoimentos:

P2 - O Colégio não está adequadamente equipado, preparado.

P4 - Na escola não há condições. Não há equipamentos e internet adequada.

P1 - Tempo e de laboratório multimídia.

Esse dado se confirmou na indicação dos fatores que impediam ou dificultavam o uso das tecnologias na prática docente dos participantes da pesquisa. O fator assinalado por cinco professores (71\% do total) fez referência genérica à falta de equipamento adequado no local de trabalho. Para reforçar tal aspecto, cinco dos sete professores que acrescentaram outros fatores à 
relação fornecida, também fizeram referência a problemas de infraestrutura, conforme se pode observar nas respostas abaixo:
P1 - O colégio dispõe de poucos equipamentos para serem utilizados por alunos e por nós mesmos.
P7 - Não há salas de informática para os alunos e professores.
P2 - O estado quer que a gente use a tecnologia, mas como se a escola não oferece equipamentos e sala própria para trabalharmos com os alunos?
de micro).
P5 - Não há temos um laboratório de informática com PCs em rede que nos permita trabalhar com 30 alunos ao mesmo tempo.
P3 - Nós professores, não temos muito tempo para ficar montando e desmontando equipamentos, tipo data show.

Considerando que a instituição em que se realizou a pesquisa foi uma escola da rede estadual, como todas as outras onde a "Nova EJA" se implantaria sob a égide de um modelo de educação com base em recursos tecnológicos, pareceu urgente a necessidade de desenvolvimento de ações no sentido de definir uma posição sobre o uso deles. Nesse sentido, vale destacar o que afirmou Kenski (2003, p. 54) sobre a relação entre o espaço da escola e a sua proposta de ensino, uma vez que "a disposição e o uso de móveis e equipamentos nas salas e nos laboratórios definem a ação pedagógica (...) O espaço é uma das linguagens mais poderosas para dizer do fazer da escola"

Ainda segundo a autora, as questões de estrutura, recurso material e compra deles, estariam diretamente ligadas ao modelo de educação tecnológica que a escola pretenderia oferecer aos seus alunos (KENSKI 2003, p. 54).

\subsection{Características necessárias aos docentes}

Ramal (2002, p. 191-203 apud Lévy, 2005) nomeou o profissional responsável por trabalhar com as novas tecnologias na educação como "arquiteto cognitivo". Tratou do conceito, desdobrando-o em quatro aspectos:

1) "O arquiteto cognitivo é um profissional" - a autora afastou do perfil desse profissional a concepção de mestre por vocação ou dom natural e o caracterizou como aquele preocupado com a sua formação pedagógica. Algumas declarações dos participantes de pesquisa destacaram a importância de sua formação assim como a especificidade de sua atuação:

P4 - Atualização permanente, inclusive quanto ao uso das novas tecnologias; disponibilidade de tempo para tal.

P6 - [...] atualização constante desse professor (autonomia profissional);

P3 - Ser um usuário; estar atualizado com relação ao q/ é produzido e difundido nessa área.

P2 - O professor deve atualizar-se e buscar conhecimentos na área para poder utilizar a tecnologia com segurança e facilidade. 
P1 - Acho que o professor de modo geral tem que ter a facilidade de aceitar desafios, que neste caso seria o de qualificar e atualizar sobre as tecnologias educacionais mais recentes.

P7 - Ser instrumentalizado, atualizado.

II) "O arquiteto cognitivo é um profissional capaz de traçar estratégias e mapas de navegação que permitam ao aluno empreender, de forma autônoma e integrada, os próprios caminhos de construção do (hiper)conhecimento em rede" - As mudanças nas formas de construção do saber fazem pensar a necessidade de repensar as teorias pedagógicas, considerando o novo contexto da educação. O aluno vivencia um processo cultural no qual a sua relação com o conhecimento e com o mundo passa pela incorporação das tecnologias, o que pode desencadear novas e diferentes formas de aprender. Desse modo, o grupo se posicionou seguinte maneira quanto as características necessárias ao profissional que vai trabalhar nesse novo contexto de ensino-aprendizagem:

P5 - [...] domínio do uso das tecnologias; criatividade na sua utilização; planejamento prévio das atividades.

P6 - Primeiro o professor deve conhecer, selecionar o que e com o que trabalhar... algo que complete os conhecimentos traçados pelo professor como necessários, dentro dos seus objetivos.

P1 - Ser bem informado e saber relacionar os temas com os recursos disponíveis; ter claro que as tecnologia são meios para estimular, ilustrar e possibilitar outro olhar $\mathrm{p} /$ o que está sendo debatido.

P3 - Saber relacionar tecnologia com educação.

P2 - Conhecer e utilizar adequadamente a seus objetivos.

III) "O arquiteto cognitivo também é um profissional capaz de traçar estratégias e mapas de navegação que permitam ao aluno empreender, de forma autônoma e integrada, ospróprios caminhos de construção do (hiper)conhecimento em rede; assumindo, para isso, uma postura consciente de reflexão-na-ação" - Considerando que a formação docente nem sempre o instrumentaliza o futuro professor para as situações a serem vivenciadas no cotidiano escolar, o docente precisaria ter a postura dentre as quais estaria a de um investigador atento e crítico, reflexivo. A importância do ato de refletir sobre a prática e transformá-la em conhecimento aparece claramente nas falas dos docentes:

P1 - As características de um professor-pesquisador, curioso, interessado nas inovações pedagógicas-tecnológicas, porém crítico e flexível para aprender com os alunos e em interação com o grupo.

P3 - Abertura para aprender sempre tanto sobre as tecnologias como sobreo uso que os alunos fazem dessas tecnologias.

P2 - Penso que o professornecessita inicialmente ter o desejo de aventura-se, precisa ser curioso, estar aberto ao novo e ter espírito de pesquisador. Ser um eterno aprendente. 
IV) "O arquiteto cognitivo é um profissional capaz de traçar estratégias e mapas de navegação que permitam ao aluno empreender, de forma autônoma e integrada, os próprios caminhos de construção do conhecimento em rede; assumindo, para isso, uma postura consciente de reflexão-na-ação e fazendo um uso crítico das tecnologias como novos ambientes de aprendizagem" - É preciso ter clareza de que o uso da tecnologia é uma forma de mediação dos processos pedagógicos e que não pode implicar em uma violação de valores ou em ignorar questões éticas. Quanto a esse aspecto, os docentes pesquisados apontam algumas das seguintes características necessárias ao professor para a utilização das tecnologias com fins educacionais

P5 - Conversar com colegas os usos, prós e contras do uso das tecnologias.

P4 - Usar as tecnologias como apoio, não deixando que substitua seu trabalho.

P6 - Entender a tecnologiacomo um recurso. Tendo em mente que pode tanto ajudar, quanto comprometer o trabalho.

Como pudemos observar, a fim de desenvolver as habilidades exigidas para a utilização das tecnologias da informação e da comunicação na prática docente, o grupo de professores atuantes no programa "Nova EJA" apontou para a necessidade de mobilizar saberes provenientes de várias fontes: saberes profissionais, disciplinares, curriculares e da experiência (TARDIF, 2000).

Importante ressaltar que para além do conhecimento técnico, próprio da disciplina, do currículo e da vivência,os docentes também relacionaram o uso das novas tecnologias da informação e da comunicação na educação aos seguintes aspectos: interesse próprio, criatividade, planejamento e acesso.

\section{CONSIDERAÇÕES}

O recorte feito para análise das contribuições dos docentes nos instigou a elaborar reflexões para a compreensão do posicionamento desses profissionais da educação, frente ao desafio de incorporar à sua prática cotidiana, as tecnologias da informação e comunicação.

No que se referiu aos recursos tecnológicos mais utilizados, foi possível verificar que alguns recursos como o data show e a televisão tiveram seu uso consolidado na escola. Já o computador foi utilizado nas atividades com os alunos por alguns poucos professores do grupo pesquisado, embora fosse considerável a importância do uso de ambientes virtuais para atividades de comunicação pessoal e lazer.

Notamos na análise dos dados, que os maiores obstáculos para a utilização de computadores com fins pedagógicos, de acordo com os motivos apontados pelos professores, foram o fato de a escola não disponibilizar de equipamentos em números suficientes e ligados em rede para serem utilizados pelos alunos, como defendeu Kenski (2003, p. 71), "[...] para que a escola possa estar conectada ao ambiente tecnológico das redes é preciso, antes de tudo, possuir a infra-estrutura adequada". 
No que se referiu às características necessárias ao professor para utilizar dos recursos tecnológicos, percebeu-se que o grupo tinha conhecimento da complexidade do desafio que estava implicado nesse novo saber, tanto que as características, elencadas apontaram para habilidades necessárias para utilização das tecnologias como mediadoras no processo de ensino e aprendizagem.

Notório, sob a perspectiva de Tardif (2014), que vivemos uma época em que as novas tecnologias são constitutivas das práticas sociais de interação. Contudo, estar matriculados em cursos de formação (como consta na proposta da "Nova EJA"), não significa acreditar que, o professor reinventará seu fazer pedagógico, incorporando os recursos tecnológicos no cotidiano da sala de aula. Para fazer uso dessas tecnologias de informação e comunicação na sua prática docente, os docentes apontaram a necessidade de conhecimentos que deveriam ser construídos na formação profissional inicial, nas instituições de educação e programas de formação docente.

Por outro lado, caberia à instituição escolar não só o fornecimento da infraestrutura necessária para o uso das tecnologias de informação na prática docente mas também a manutenção dessa infraestrutura (KENSKI, 2003).

Assim, esse novo paradigma educacional vinculado a profissionalização docente, nos leva a refletir sobre a necessidade de repensar as propostas de EJA, bem como sua vinculação com as tecnologias da informação.Desse modo, entende-se que os aspectos discutidos nesse trabalho, constituem dados, de certo modo relevantes para a elaboração de propostas de ação para a escola, tanto no sentido de se adequar às necessidades estruturais quanto de formação dos seus profissionais. Compete, entretanto, à comunidade escolar (compreendendo todos os seus atores) decidir que tipo de formação e que ações deverão ser priorizadas a fim de viabilizar a execução do seu projeto político pedagógico, com vistas ao uso das novas tecnologias da informação na educação na EJA.

\section{REFERÊNCIAS}

1. ARROYO, M. Balanço da EJA: o que mudou nos modos de vida dos jovens-adultos populares? In:Plenária do Fórum Mineiro de Educação de Jovens e Adultos, 67, 29 de junho de 2007.

2. BÉLANGER, P. Tendências en la política de educación de adultos. In: Educación de Adultos y desarollo - Instituto de la cooperación Internacional de la Asociación Alemana para Educación de Adultos. N.47, 1996, p.21-32

3. BRASIL. LEI N 9394/96. Diretrizes e Bases da Educação Nacional. Setembro de 1996. Editora do Brasil.

4.

. Parâmetros curriculares nacionais: ensino médio/ Secretaria de Ensino Médio. Brasília, MEC/SEM, 1999.

5. BRASILEIRO, S. Juventude e novas tecnologias: implicações para a educação de jovens e adultos. REUNIÃO ANUAL DA ASSOCIAÇÃO NACIONAL DE PÓSGRADUAÇÃO E PESQUISA EM EDUCAÇÃOANPEd, 25a , Caxambú/MG. Anais..., Caxambu, p. 112-127, 2002. 
6. BLIKSTEIN, P.; ZUFFO, M. K. As sereias do ensino eletrônico. In: SILVA, M. (Org.) Educação online. São Paulo: Edições Loyola, 2003. p. 23-38.

7. CARNEIRO, R.Informática na educação: representações sociais do cotidiano. 2. ed. São Paulo: Cortez, 2002.

8. CASTELL, M. A Sociedade em rede: do Conhecimento à Àção Política.Debates, 2005.

9. CAVANAGH, C. El aprendizaje de los adultos, los medios de comunicación, la cultura y las nuevas tecnologias de la información y comunicación. In: V Confintea. Tema 7,1997,p.161-178.

10. FREIRE, P. Desafios da educação de Adultos frente à nova reestruturação tecnológica. In: Seminário Internacional Educação e Escolarização de Jovens e Adultos (1996, São Paulo:IBEAC) v.1. Brasília: MEC, 1997 p.264-274.

11. GADOTTI, Moacir. As muitas lições de Paulo Freire. IN: Paulo Freire: poder, desejo e memórias de libertação. Trad. Márcia Moraes, ArtMed, Porto Alegre, 1998, p.25-34.

12. GOMEZ, M. V. Paulo Freire: Re-leitura para uma teoria da informática na educação. São Paulo: Instituto Paulo Freire, 1999.

13. IRELAND, T. D. Revisitando a CONFINTEA: sessenta anos de defesa e promoção da educação de adultos. Revista Brasileira de Educação de Jovens e Adultos, v. 1, n. 1, p. 14-28, 2013.

14. KENSKI, V. M. Tecnologias e ensino presencial e a distância.Campinas, SP: Papirus, 2003.

15. KNOBEL, M. Paulo Freire e a juventude digital em espaços marginais. In: Paulo Freire: poder, desejo e memórias de libertação. Trad. Márcia Moraes, ArtMed, Porto Alegre, 1998, p.175-189.

16. LÉVY,P. Cibercultura.São Paulo: Editora 34, 2005.

17. . As tecnologias da inteligência: o futuro do pensamento na era da informática.

São Paulo : Editora 34, 1993.

18. MANUAL DE ORIENTAÇOES NOVA EJA. Disponível em: http://projetoseeduc.cecierj.edu.br/prin cipal/download/Manual_projeto_nova_EJA_final_2014.pdf

19. MASETTO, M. T. Mediação pedagógica e o uso da tecnologia. In: MORAN, J. M.; MASETTO, M., T.; BEHRENS, M. A. Novas tecnologias e mediação pedagógica.8. ed. Campinas, SP: Papirus, 2004. p. 133-173.

20. NISKIER, A. Tecnologia educacional: uma visão política. Petrópolis, RJ: Vozes, 1993.

21. OGIBOSKI, V. Reflexões sobre a tecnociência: uma análise crítica da sociedade tecnologicamente potencializada. 2012. Dissertação mestrado em Ciência, Tecnologia e Sociedade - Universidade Federal de São Carlos, São Carlos, 2012.

22. PONTE, J. P. da. Tecnologias de informação e comunicação na formação de professores: Que desafios? Revista Ibero-Americana de Educación. OEI. N. 24, septiembre/diciembre, 2000. Disponível em http://www.oei.es/revista.htm. Acesso em 07/08/14.

23. RAMAL, A. C. Educação na cibercultura: hipertextualidade, leitura, escrita e aprendizagem. Porto Alegre: Artmed, 2002. 
24. TAJRA, S. F. Informática na educação:professor na atualidade. São Paulo: Érica, 1998.

25. TARDIF, M. Saberes docentes e formação profissional. Editora Vozes Limitada, 2014.

26. Saberes profissionais dos professores e conhecimentos universitários. Revista Brasileira de Educação, v. 13, n. 5, 2000.

27. .Os professores face ao saber docente: esboço de uma problemática do saber docente. Revista Teoria e Educação, Porto Alegre, n. 4, 1991. p. 215-233.

28. UNESCO. Declaração de Hamburgo sobre a Educação de Adultos e Plano de Ação para o Futuro. In: Conferência Internacional sobre Educação de Adultos. Hamburgo, Alemanha:jul./1997. 